\title{
Bulk Ingredient for Animal Drug Compounding
}

National Cancer Institute

\section{Source}

National Cancer Institute. Bulk Ingredient for Animal Drug Compounding. NCI Thesaurus. Code C98252.

A marketing category for bulk ing redients intended for individual compounding for veterinary patients, regardless of the existence of a prescription. 